\title{
No evidence of linkage or diabetes-associated mutations in the transcription factors BETA2/NEUROD1 and PAX4 in Type II diabetes in France
}

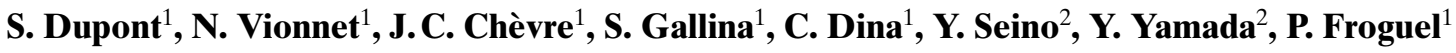 \\ ${ }^{1}$ Centre National de la Recherche Scientifique EP-10, Institut Pasteur de Lille, Lille, France \\ ${ }^{2}$ Department of Metabolism and Clinical Nutrition Graduate School of Medicine, Kyoto University, Japan
}

\section{Abstract}

Aims/hypothesis. The identification of mutations in hepatocyte nuclear factors- $1 \alpha,-4 \alpha,-1 \beta$ and insulin promoter factor-1 in maturity onset diabetes of the young (MODY) has highlighted the role that transcription factors may have in the development of diabetes. This result has focused molecular genetic studies of diabetes on other transcription factors expressed in the pancreatic beta cell. The basic helixloop-helix transcription factor BETA2/NEUROD1 (gene symbol, NEUROD1) and the paired box homeodomain transcription factor PAX4 (PAX4) have an important role in islet and beta-cell development. We have examined the contribution of these transcription factors to the development of MODY and late-onset Type II (non-insulin-dependent) diabetes mellitus.

Methods. Linkage studies have been done in MODY families reported to have no mutations in the five known MODY genes and in affected sibling pairs from families with late-onset Type II diabetes. Mutation screening of the coding regions of both genes was also realised by SSCP followed by sequencing in MODY patients and in probands with late-onset Type II diabetes.

Results. There was no evidence of linkage with the markers for NEUROD1 and PAX4 either with MODY or late-onset Type II diabetes. Mutation screening showed single nucleotide polymorphisms, several of which resulted in amino acid substitutions : NEUROD1, Ala45Thr; PAX4, Pro321His and Pro334Ala. These amino acid sequence variants were not associated with Type II diabetes.

Conclusion/interpretation. Our results indicate that NEUROD1 and PAX4 are not a common cause of either MODY or late-onset Type II diabetes in the French Caucasian population. [Diabetologia (1999) 42: 480-484]

Keywords MODY, late-onset Type II diabetes, transcription factors, PAX4, BETA2/NEUROD1, SSCP.
There is increasing interest in the use of genetic approaches to provide a better understanding of the

Received: 24 August 1998 and in revised form: 12 November 1998

Corresponding author: Dr. P. Froguel, CNRS EP10, Institut Pasteur de Lille, 1 rue du Professeur Calmette, F-59019 Lille Cedex, France

Abbreviations: MODY, Maturity onset diabetes of the young; HNF, hepatocyte nuclear factor; IFG; impaired fasting glucose; IPF, insulin promoter factor; MLS, maximum LOD score; SSCP, single strand conformation polymorphism; WHO, World Health Organisation. causes of Type II (non-insulin-dependent) diabetes mellitus and how it develops. These studies have shown that heterozygous mutations in the glycolytic enzyme glucokinase and the transcription factors hepatocyte nuclear factor (HNF) $-1 \alpha,-4 \alpha$ and $1 \beta[1$, 2] and insulin promoter factor-1 (IPF1) [3] can cause MODY (maturity onset diabetes of the young) and, in rare cases, late onset Type II diabetes [4].

These findings have highlighted the importance of transcription factors expressed in the pancreatic beta cell in the development of Type II diabetes. Functional studies of other transcription factors suggested their potential involvement in the pathogenesis of diabetes. Knock-out mice lacking BETA2/NEUROD1, 
a member of the basic helix-loop helix family of transcription factors which activates the insulin gene transcription [5], exhibited a striking reduction in the number of beta cells, failed to develop mature islets and died perinatally from severe diabetes [6]. PAX4 is a member of the paired box homeodomain family. It is expressed in the early pancreas but is later restricted to beta cells. Inactivation of PAX4 results in the absence of mature insulin and somatostatin-producing cells in the pancreas and an increase of glucagon-producing alpha cells [7].

To examine the contribution of NEUROD1 and PAX4 to the development of MODY and late-onset Type II diabetes, we did family linkage analyses using markers located in the vicinity of these genes. In addition, we screened these genes for mutations in MODY patients reported to have no mutations in the five known MODY genes (MODY X patients) and in late-onset Type II diabetic probands having possibly a primary defect in insulin secretion. A group of obese late-onset Type II diabetic probands were also screened for mutations in PAX4.

\section{Subjects and methods}

All families and patients with late-onset Type II diabetes used for the screening and association studies came from 550 French Caucasian Type II diabetic pedigrees recruited through a multimedia campaign.

Linkage studies. Linkage studies were done using markers located near NEUROD1 (D2S1391 and D2S364) and PAX4 (D7S504, D7S635). We first localized NEUROD1 within the linkage map of chromosome 2 using the Genebridge 4 Radiation Hybrid Panel (Research Genetics, Huntsville, Ala., USA) and analysed data using the computer program RHMAP3.0 from the Statistical Package for Multipoint Radiation Hybrid Mapping [8]. The gene NEUROD1 was localized between markers D2S324 (191 cM) and D2S118 (197 cM). The markers D2S1391 and D2S364 (193 cM) lie within this $6 \mathrm{cM}$ interval. The $P A X 4$ gene was localized on chromosome 7 at $133.8 \mathrm{cM}$ [9] and D7S686 (132 cM) and D7S504 (133 cM) were selected as markers for $P A X 4$.

The D2S364 and D7S504 markers were typed in 8 pedigrees suitable for linkage analysis among the 11 french MODY X families described previously [10] using automated-fluorescent based procedures. Since one marker per locus is possibly not sufficient to evaluate the role that a gene can have in a complex disease such as late-onset Type II diabetes, D2S364, D2S1391, D7S504 and D7S686 were typed in members of 149 late-onset Type II diabetes families. These families came from the group of 172 pedigrees described previously [11] from which we excluded families with bilineal transmission of diabetes. Affected status was determined by clinical and biological examinations including oral glucose tolerance testing. Two different categories of affected status based on severity of hyperglycaemia were considered. We used both conservative criteria for Type II diabetes (referred to as "overt Type II diabetes") as newly defined by the World Health Organization (WHO) in 1997 [12], which yielded 395 affected people, of whom $85 \%$ were being treated with oral hyperglycaemic agents or insulin and less stringent criteria for affected status (referred to as "all affected") in-
Table 1. Clinical characteristics of the probands studied

\begin{tabular}{lll}
\hline Clinical characteristics & $\begin{array}{l}58 \text { age at onset } \\
\leq 45 \text { years, } \\
\text { lean, patients }\end{array}$ & $\begin{array}{l}\text { 23 obese } \\
\text { patients }\end{array}$ \\
\hline Sex ratio (\% men) & 62 & 69.5 \\
present age (years) & $55 \pm 13$ & $56 \pm 9.1$ \\
age at diagnosis (years) & $36 \pm 7$ & $42.8 \pm 10.9$ \\
BMI $\left(\mathrm{kg} / \mathrm{m}^{2}\right.$ ) & $24 \pm 2.1$ & $31.4 \pm 2.6$ \\
Fasting plasma glucose (mmol/1) & $9.01 \pm 2.6$ & $10.2 \pm 3.09$ \\
Fasting insulinaemia (mU/l) & $7.05 \pm 5.2$ & $12.7 \pm 10.1$ \\
Current treatments (\% probands): & & \\
$\quad$ oral hypoglycaemic agents & 51.6 & 74 \\
$\quad$ insulin & 27.5 & 4.3 \\
$\quad$ hypoglycaemic agents + insulin & 8.4 & 8.7 \\
diet & 1.7 & 4.3 \\
none & 10.8 & 8.7 \\
\hline
\end{tabular}

cluding overt Type II diabetes, impaired glucose tolerance (IGT) and impaired fasting glucose (IFG) according to WHO criteria 1997, which yielded 470 affected people.

Mutation screening of NEUROD1 and PAX4. The coding regions and flanking introns of NEUROD1 (exon 2 - the first one is untranslated) and PAX4 (nine exons) genes were screened for mutations in one diabetic proband from each of the 11 MODY $\mathrm{X}$ pedigrees and in 58 subjects with late-onset Type II diabetes. The latter were lean $\left(B M I \leq 27 \mathrm{~kg} / \mathrm{m}^{2}\right)$ with Type II diabetes diagnosed before 46 years of age, features which might indicate a primary defect in insulin secretion (Table 1). In addition, we screened $P A X 4$ for mutations in 23 obese Type II diabetic probands belonging to the 23 families which contributed to the indication of linkage obtained at D7S686 (Table 1).

We carried out PCR using primer pairs yielding fragments of a size of 156 to $338 \mathrm{bp}$ : an amplicon per exon for $P A X 4$ and four overlapping segments for the exon 2 (1068 bp) of the NEUROD1 gene. We used a SSCP (Single Strand Conformation Polymorphism) protocol based on fluorescent end-labelling primer, using an ABI Prism 377 DNA sequencer, as developed in our laboratory [13]. The gel temperature on the automated sequencer was maintained at $20^{\circ} \mathrm{C}$ with an external cooling system.

For each DNA variant found by SSCP, PCR products were directly sequenced on both strands using an Ampli Taq FS dRhodamine Terminator Cycle sequencing kit (PE, Applied Biosystems, Foster City, Calif., USA) and an automated sequencer (ABI 377).

Association studies. Association studies were conducted in 198 unrelated Type II diabetic patients (58 probands plus 140 subjects) and in 114 unrelated normoglycaemic spouses from the same families. The rare PAX4 Pro334Ala substitution was tested in an additional 228 Type II diabetic and 112 control subjects (Table 1).

The NEUROD1 Ala45Thr and PAX4 Pro321His and Pro334Ala mutations result in a loss of a MwoI (New England Biolabs, Beverly, USA) site and a gain of MaeIII (Boehringer Mannheim, Mannheim, Germany) and Cac8I (New England Biolabs) sites, respectively and, therefore, subjects were screened for these substitutions by PCR-RFLP. The DNA fragments were separated on a $2 \%$ agarose gel and made visual by ethidium bromide staining. 
Table 2. $P A X 4$ and NEUROD1 gene variants

\begin{tabular}{|c|c|c|c|c|c|c|c|}
\hline \multirow[t]{2}{*}{ Gene } & \multirow[t]{2}{*}{ a } & \multirow{2}{*}{$\begin{array}{l}\text { exon/ } \\
\text { intron }\end{array}$} & \multirow[t]{2}{*}{ codon/nucleotide } & \multirow[t]{2}{*}{ nucleotide change } & \multicolumn{3}{|c|}{ Genotype frequency $(\%)^{\mathrm{b}}$} \\
\hline & & & & & 198 Type II diabetic & 114 controls & \\
\hline \multicolumn{8}{|c|}{ NEUROD1 } \\
\hline & $\mathrm{M}, \mathrm{N}$ & exon2 & codon 45 & $\mathbf{G C C}$ (Ala) / ACC (Thr) & $36.1 / 43.3 / 20.6$ & $38.1 / 46 / 15.9$ & $p=\mathrm{NS}$ \\
\hline \multicolumn{8}{|l|}{$P A X 4$} \\
\hline & $\mathrm{N}$ & intron3 & $\mathrm{nt}+35$ & $\mathrm{G} / \mathrm{A}$ & - & - & - \\
\hline & $\mathrm{M}, \mathrm{N}, \mathrm{O}$ & exon4 & codon 150 & GGC (Gly) / GGT (Gly) & - & - & - \\
\hline & $\mathrm{M}, \mathrm{N}, \mathrm{O}$ & intron4 & nt 96 & del C & - & - & - \\
\hline & $\mathrm{N}$ & exon5 & codon 204 & GAC (Asn) /GAT (Asn) & - & - & - \\
\hline & $\mathrm{M}, \mathrm{N}, \mathrm{O}$ & exon9 & codon 321 & CCC (Pro) / CAC (His) & $63.3 / 29.1 / 7.6$ & $59.3 / 36.3 / 4.4$ & $p=\mathrm{NS}$ \\
\hline & $\mathrm{N}$ & exon9 & codon 334 & CCT (Pro) / GCT (Ala) & $99.5 / 0.5 / 0$ & $100 / 0 / 0$ & $p=\mathrm{NS}$ \\
\hline & $\mathrm{N}, \mathrm{O}$ & 3'-UT & $\mathrm{nt}+33$ & $\mathrm{~A} / \mathrm{C}$ & - & - & - \\
\hline
\end{tabular}

${ }^{a} \mathrm{M}, \mathrm{N}, \mathrm{O}$ correspond to variations detected among MODY, lean + age at diagnosis $\leq 45$ years late-onset Type II diabetic and late-onset Type II diabetic obese individuals studied to screen the genes. ${ }^{\mathrm{b}}$ percentage of normal homozygotes / heterozygotes / homozygotes for the variant

\section{Statistics}

Linkage analyses. The lod-score calculations in MODY families have been computed as previously [14]. Analyses in sibpairs with late-onset Type II diabetes were done on the overall sample and on three different subgroups comprising affected sib-pairs with an age at diagnosis of 45 years or less, or obese $\left(\mathrm{BMI}>27 \mathrm{~kg} / \mathrm{m}^{2}\right)$ or lean $\left(\mathrm{BMI} \leq 27 \mathrm{~kg} / \mathrm{m}^{2}\right)$ sib-pairs. Evidence for linkage was sought using three non-parametric affected sib-pair methods which were shown to display different statistical properties: the Haseman-Elston sib-pair method implemented in the computer program SIBPAL of the SAGE package [15], the MLS (maximum LOD score) and exclusion score methods computed using the program MAPMAKER/ SIBS [16] and a third method based on the number of shared and non-shared alleles among affected sib-pairs computed from informative meioses with the program SIBPAIR of the ANALYZE package [17]. To evaluate the power of our linkage studies, we tested ascending values of recurrent sibling risk $(\lambda s)$ using the program MAPMAKER/SIBS [15], under the no dominance variance hypothesis, and retained the $\lambda$ s for which the exclusion score was lower than -2. Distance between adjacent markers were checked using MLINK program of the VITESSE package [18].

Association analyses. Genotype frequencies in the Type II diabetic and control groups were compared using chi-squared ratios calculated under dominant, codominant and recessive models. We used ANOVA to test the association between each polymorphism and BMI or age at diagnosis of diabetes (we excluded the group of 58 Type II diabetic patients used for the screening as they were selected according to those clinical data).

\section{Results}

$M O D Y$. Cumulative lod-scores showed exclusion of linkage with diabetes with the NEUROD1 (LOD score at $\left.\theta_{0}=-12.16\right)$ and PAX4 (-13.16) loci in eight MODY $\mathrm{X}$ families suitable for linkage analysis. Moreover, none of the LOD scores indicated evi- dence of linkage in any of the MODY pedigrees: they ranged from -3.97 to 0.01 for D2S364 and from -4.26 to 0.94 for D7S504.

Mutation screening of the NEUROD1 gene showed only the previously described Ala45Thr polymorphism in NEUROD1 [19]: six probands were heterozygous and three were homozygous. In the PAX4 gene, three silent mutations were identified and a heterozygous C-to-A transversion in exon 9 resulting in a proline to histidine substitution (Pro321His) being found in three patients (Table 2).

Late-onset Type II diabetes. Distances between adjacent markers in our sample, as determined by MLINK were $3 \mathrm{cM}$ between D2S1391 and D2S364 and $2 \mathrm{cM}$ between D7S504 and D7S686, which is similar to the critical distance maps (see Methods), thus indicating a reliable quality of the genotyping.

We found no evidence of linkage between diabetes and the NEUROD1 D2S1391, D2S364, or the PAX4 D7S504 markers in any of the subgroups studied regardless of affection status and type of analysis done. There was also no evidence for PAX4-D7S686 linkage in the overall group but some indication for linkage with diabetes in the subgroup of 102 obese diabetic sib-pairs with excess allele sharing $0.57 \pm 0.28$ (mean proportion of alleles $\pm \mathrm{SD}, p=0.006$ ) using SIBPAL; $\quad$ MLS $=1.97 \quad(p=0.002) \quad$ using MAPMAKER/SIBS; and 97.1 shared alleles/67.9 not shared alleles $(p=0.01)$ using SIBPAIR (Table 3$)$.

We screened NEUROD1 for mutations in 58 Type II diabetic probands with features consistent with a primary defect in insulin secretion (Table 2). The screening showed the Ala45Thr polymorphism and a heterozygous $\mathrm{C}$-to- $\mathrm{T}$ transition in intron 1, 32 nucleotides upstream of exon 2 , in one subject. This substitution did not co-segregate with Type II diabetes in his family. 
Table 3. Results of late-onset Type II diabetic sib-pair analyses

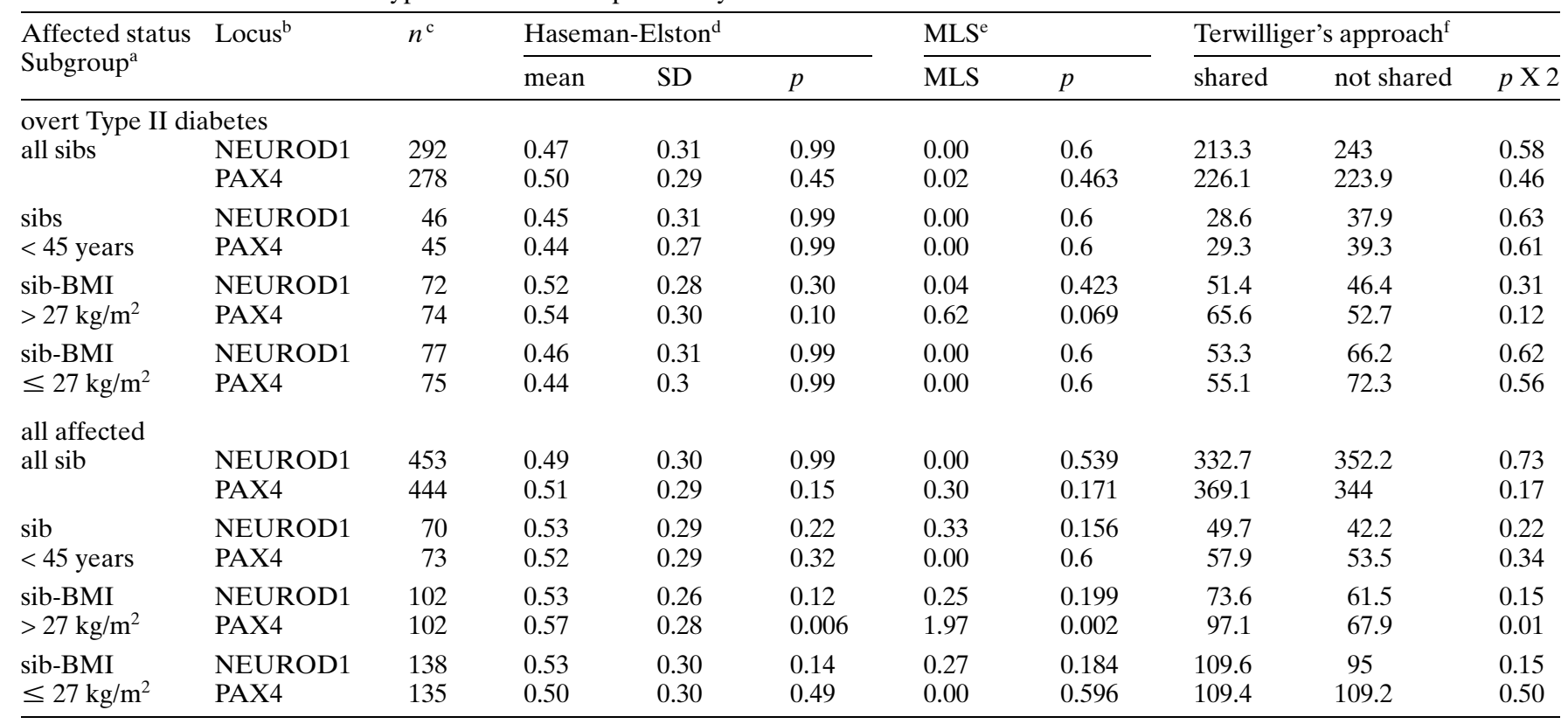

${ }^{a}$ see methods for description of affected status and subgroups.

${ }^{b}$ For each locus and subgroup, only the result of the marker indicating the highest score is shown. ${ }^{\mathrm{c}} n$ is the total number of affected sib-pairs genotyped for a given marker. ${ }^{\mathrm{d}}$ Estimated mean proportion and standard deviation (SD) of IBD alleles

and the corresponding $p$ value using the Haseman-Elston method. ${ }^{\mathrm{e}}$ Maximum LOD score and the corresponding $p$ value. ${ }^{f}$ Number of shared and non-shared IBD alleles among affected sib-pairs and the corresponding $p$ value

Because of the indication of linkage detected at the PAX4 locus in the subgroup of obese diabetic sib-pairs, we selected one proband from each of the 23 families which contributed to the indication of linkage to screen for mutations in $P A X 4$. In addition, we also screened the 58 lean Type II diabetic probands described above. The four variations found in the MODY probands were identified among these 81 subjects (Table 2 ). We detected five additional single nucleotide substitutions in isolated patients, among them a C-to-G transversion in exon 9 resulting in a proline to alanine (Pro334Ala) missense mutation. This Pro334Ala substitution was only found in the heterozygous state in 1 of the 58 lean Type II diabetic subjects and did not co-segregate with diabetes in his family as it is inherited from the non-diabetic parent.

Association studies. No association was found between the NEUROD1-Ala45Thr, the PAX4-Pro321His polymorphisms and either diabetes (Table 2) or BMI or age at onset of the disease (data not shown). The Pro334Ala substitution is very rare and was not found in any of the 198 Type II diabetic or 114 control subjects systematically used for an association study or in an additional 228 Type II diabetic and 112 control subjects (Table 2).

\section{Discussion}

By linkage and screening studies, we found no evidence for NEUROD1 and $P A X 4$ genes having a role in MODY or late-onset Type II diabetic French families. The design of our study in late-onset Type II diabetic pedigrees allowed us to reach the exclusion standard score of -2 for both loci for a recurrent sibling risk $(\lambda \mathrm{s})$ of 1.2 to 1.4 in the whole sample and of 2 to 3.5 in the different sub-groups. Moreover, none of the missense mutations detected in the coding regions were associated with Type II diabetes when considering a risk ratio of at least 2 which confers a power in our study of more than $80 \%$. Thus, although we cannot exclude the presence of other mutations not detected by SSCP or located in promoters or untranslated sequences, it is improbable that a mutation in the NEUROD1 and PAX4 genes are a frequent cause of Type II diabetes. The number of subjects screened would, however, not allow us to identify any potential diabetogenic variant in any gene with a prevalence below $2 \%$.

Three other studies, investigating coding sequences of NEUROD1, also describe the detection of the Ala45Thr polymorphism through PCR-SSCP or direct sequencing in different nationality groups but no association was found with Type I (insulin-dependent) diabetes mellitus in the American group [19], MODY in the Japanese group [20] or with late-onset Type II diabetes in the Danish Caucasian group [21]. 
A recent work reported no linkage between the $P A X 4$ locus and late-onset Type II diabetes in Ashkenazi Jews [22]. Our study, together with the reports cited above, indicates that NEUROD1 and $P A X 4$ are not a common cause of either MODY or late-onset Type II diabetes.

Acknowledgements. We would like to thank Dr G. Bell from the Howard Hughes Medical Institute of The University of Chicago who provided us the NEUROD1 gene sequence. This study was supported by the Centre Hospitalier Universitaire of Lille and the Conseil Régional Nord-Pas-de-Calais grant.

\section{References}

1. Velho G, Froguel P (1997) Maturity-onset diabetes of the young (MODY), MODY genes and non-insulin-dependent diabetes mellitus. Diabetes Metab 23 [Suppl 2]: 34-37

2. Horikawa Y, Iwasaki N, Hara M et al. (1997) Mutation in hepatocyte nuclear factor-1 beta gene (TCF2) associated with MODY. Nat Genet 17: 384-385

3. Stoffers DA, Ferrer J, Clarke WL, Habener JF (1997) Early-onset type-II diabetes mellitus (MODY4) linked to IPF1. Nat Genet 17: 138-139

4. Hani EH, Suaud L, Boutin P et al. (1998) A missense mutation in hepatocyte nuclear factor- 4 alpha, resulting in a reduced transactivation activity, in human late-onset non-insulin-dependent diabetes mellitus. Clin Invest 101: 521-526

5. Naya FJ, Stellrecht CM, Tsai MJ (1995) Tissue-specific regulation of the insulin gene by a novel basic helix-loop-helix transcription factor. Genes Dev 9: 1009-1019

6. Naya FJ, Huang HP, Qiu Y et al. (1997) Diabetes, defective pancreatic morphogenesis, and abnormal enteroendocrine differentiation in BETA2/neuroD-deficient mice. Genes Dev 11: 2323-2334

7. Sosa-Pineda B, Chowdhury K, Torres M, Oliver G, Gruss P (1997) The $\mathrm{Pa} \times 4$ gene is essential for differentiation of insulin-producing beta cells in the mammalian pancreas. Nature 386: 399-402

8. Lunetta KL, Boehnke M, Lange K, Cox DR (1996) Selected locus and multiple panel models for radiation hybrid mapping. Am J Hum Genet 59: 717-725
9. http://cedar.genetics.sotonac.uk/pub/chrom7/map.html

10. Chevre JC, Hani EH, Boutin P et al. (1998) Mutation screening in 18 Caucasian families suggest the existence of other MODY genes. Diabetologia 41: 1017-1023

11. Vionnet N, Hani EH, Lesage S et al. (1997) Genetics of NIDDM in France: studies with 19 candidate genes in affected sib pairs. Diabetes 46: 1062-1068

12. Report of the Expert Committee on the Diagnosis and Classification of Diabetes Mellitus. (1997) Diabetes Care 20: $1183-1197$

13. Boutin P, Hani EH, Vasseur F et al. (1997) Automated fluorescence-based screening for mutation by SSCP: use of universal M13 dye primers for labeling and detection. Biotechniques 23: 358-362

14. Vaxillaire M, Boccio V, Philippi A et al. (1995) A gene for maturity onset diabetes of the young (MODY) maps to chromosome 12 q. Nat Genet 9: 418-423

15. S.A.G.E: Statistical Analysis for Genetics Epidemiology, Release 2.2. (1994) Computer program package available from the Department of Biometry and Genetics, LSU Medical Center, New Orleans

16. Holmans P (1993) Asymptotic properties of affected-sibpair linkage analysis. Am J Hum Genet 52: 362-374

17. ftp://linkage.cpmc.columbia.edu/software/analyze

18. Connell JR, Weeks DE (1995) The VITESSE algorithm for rapid exact multilocus linkage analysis via genotype set-recording and fuzzy inheritance. Nat Genet 11: 402-408

19. Owerbach D, Naya FJ, Tsai MJ, Allander SV, Powell DR, Gabbay KH (1997) Analysis of candidate genes for susceptibility to type I diabetes: a case-control and family-association study of genes on chromosome 2q31-35. Diabetes 46: 1069-1074

20. Furuta H, Horikawa Y, Iwasaki N et al. (1998) Beta-cell transcription factors and diabetes: mutations in the coding region of the BETA2/NeuroD1 (NEUROD1) and $\mathrm{Nk} \times$ $2.2(\mathrm{NKX} 2 \mathrm{~B})$ genes are not associated with maturity-onset diabetes of the young in Japanese. Diabetes 47: 1356-1358

21. Hansen T, Hansen L, Urhammer S, Eiberg H, Pedersen O (1998) Studies of the variability in the genes encoding the insulin promoter factor- 1 and its upstream activator NEUROD/BETA2 in Danish caucasian NIDDM families. Diabetologia [Suppl 1] A110

22. Tao T, Wasson J, Bernal-Mizrachi E et al. (1998) Isolation and characterization of the human PAX4 gene. Diabetes 47: $1650-1653$ 